\title{
Impact of Baroreflex Activation Therapy on Renal Function - A Pilot Study
}

\author{
Manuel Wallbach ${ }^{a} \quad$ Luca-Yves Lehnig $^{a} \quad$ Charlotte Schroer $^{b} \quad$ Gerd Hasenfuss $^{b}$ \\ Gerhard A. Müller $^{\mathrm{a}}$ Rolf Wachter ${ }^{\mathrm{b}}$ Michael J. Koziolek ${ }^{\mathrm{a}}$ \\ aDepartment of Nephrology and Rheumatology and bepartment of Cardiology and Pulmonology, \\ Georg-August-University Goettingen, Germany
}

\section{Key Words}

Baroreflex activation therapy $\cdot$ Resistant hypertension .

Hypertensive nephropathy · Albuminuria · Proteinuria

\begin{abstract}
Background/Aims: Resistant hypertension and chronic kidney disease (CKD) are interlinked via sympathetic overdrive. Baroreflex activation therapy (BAT) has been shown to chronically reduce blood pressure (BP) in patients with resistant hypertension. The effect of BAT on renal function in CKD patients with resistant hypertension has not been reported. The aim of this study was to investigate the effect of sympathetic inhibition on renal function in CKD patients. Methods: 23 CKD patients with resistant hypertension were prospectively treated with BAT. Analyses were performed before and 6 months after the start of BAT. The renal function was analyzed by creatinine, cystatin $C$, glomerular filtration rate (GFR), renin, aldosterone, fractioned and 24-hour sodium excretion and analyses of urine marker proteins. The purpose of the control group was to investigate the influence of treating patients in a center for hypertension and regression to the mean on investigated variables. Results: The office mean BP decreased from $116.9 \pm 20.9 \mathrm{~mm}$ Hg to $104.2 \pm 22.2 \mathrm{~mm}$ $\mathrm{Hg}(\mathrm{p}<0.01)$, while the number of prescribed antihyperten-
\end{abstract}

sive classes decreased from $6.6 \pm 1.6$ to $6.1 \pm 1.7(p=0.02)$. Proteinuria and albuminuria decreased from a median of 283.9 and 47.7 to $136.5(p=0.01)$ and $45.0 \mathrm{mg} / \mathrm{g}$ creatinine $(p=0.01)$ with pronounced effects in higher CKD stage III + IV compared to I + II $(p<0.01)$. CKD-EPI cystatin C equation improved from $53.6 \pm 22.7$ to $60.4 \pm 26.1 \mathrm{ml} / \mathrm{min}(p=0.02)$. While creatinine and GFR were impaired after a period of 6 months, no changes of proteinuria, albuminuria, or BP were obtained in control patients. Conclusion: The data of this prospective trial demonstrate potential nephroprotective effects of BAT in therapy-resistant hypertension in CKD patients by a reduction of $\mathrm{BP}$, proteinuria and moreover, a stabilization of estimated GFR.

(c) 2014 S. Karger AG, Basel

\section{Introduction}

Resistant hypertension is defined as failure to achieve the goal blood pressure (BP) when adhering to maximally tolerated doses of 3 appropriate antihypertensive drugs including a diuretic [1]. The kidney disease: improving global outcomes (K-DIGO) guidelines for the management of BP in chronic kidney disease (CKD) recommend that both diabetic and nondiabetic patients without albu-

\section{KARGER}

(C) 2014 S. Karger AG, Basel

0250-8095/14/0404-0371\$39.50/0

E-Mail karger@karger.com

www.karger.com/ajn
M. Koziolek, MD

Department of Nephrology and Rheumatology

Georg-August-University Goettingen

Robert-Koch-Strasse 40, DE-37075 Goettingen (Germany)

E-Mail mkoziolek@med.uni-goettingen.de 
minuria suffering from non-dialysis-dependent CKD should have BP controlled $\leq 140 / 90 \mathrm{~mm} \mathrm{Hg}$, whereas BP target for patients with significant albuminuria (microalbuminuria or macroalbuminuria) with or without diabetes should be $\leq 130 / 80 \mathrm{~mm} \mathrm{Hg}$ [2]. Furthermore, according to the current definition, hypertensive patients who reach the BP target by means of four or more drugs are considered resistant $[3,4]$. On the one hand, existence of CKD is frequently associated with resistant hypertension [5]. On the other hand, observational studies suggest a strong association between hypertension or proteinuria and the risk for renal function decline or end-stage renal disease (ESRD) [6] as well as cardiovascular events.

There is documented evidence that an adrenergic activation occurs in essential hypertension, particularly in advanced stages of renal failure, and the degree of the sympathetic activation is directly related to the severity of the hypertension state [7]. The adrenergic activation, albuminuria, and a decreased glomerular filtration rate (GFR) display an adverse impact on cardiovascular morbidity and mortality in CKD patients $[7,8]$. Besides extrarenal effects, sympathetic overactivity influences renal sodium excretion and reabsorption, renal perfusion, glomerular filtration rate, and renin release $[9,10]$. Moreover, increased activity of the sympathetic nervous system is associated with estimated glomerular filtration rate (eGFR) and proteinuria suggesting that the activation of this system is a progression factor in CKD patients [11].

Recently, novel interventional treatment options to selectively suppress the sympathetic nervous system activity have become available for clinical use and might be more potent than pharmacological approaches in normalizing sympathetic overactivity, thereby affording increased nephroprotection $[12,13]$. Prior safety data about patients with resistant hypertension treated with baroreflex activation therapy (BAT) showed a mild decrease in GFR, a significant elevation in serum creatinine, and a stable albuminuria, which was to be considered a normal hemodynamic response to the drop in BP $[14,15]$. The effects of BAT are mediated by the attenuation of sympathetic as well as by the augmentation of parasympathetic activity [16], which has been demonstrated to exert clinically significant treatment benefits in cases of resistant hypertension [1]. The European Renal Best Practice Work Group suggests that this new technique should be offered only in the setting of a trial in CKD patients. However, until now there is a lack of data in these high-risk patients. Therefore, the aim of the current study is to ascertain if the inhibition of the sympathetic nervous sys- tem by BAT might exert organoprotective effects with regard to renal function in CKD patients suffering from resistant hypertension.

Here we present our data from a prospective observational trial of BAT treatment in CKD patients with resistant hypertension on proteinuria, fractioned and 24-hour sodium excretion and equations for estimating GFR as surrogates of renal damage.

\section{Methods}

\section{Patients, BAT, and Study Protocol}

CKD patients defined by the KDIGO criteria 2012 ([2] fulfilling the diagnosis of resistant hypertension [17] and BP above national and international target $(\leq 130 / 80 \mathrm{~mm} \mathrm{Hg}$ ) (DHL, http:// www.hochdruckliga.de/tl_files/content/dhl/downloads/DHLLeitlinien-2011.pdf) and ESH/ESC Guidelines [18] and [2, 19, 20]) were prospectively included into this study. Before enrolment either the secondary reason for hypertension were excluded or the patients got optimal treatment.

In particular, patients who had the combination of the following criteria were consecutively enrolled: (a) office systolic blood pressure $\geq 130 \mathrm{~mm} \mathrm{Hg}$, confirmed by multiple measurements, despite treatment with non-pharmacological measures and use of at least three antihypertensive drugs (including a diuretic) on maximally tolerated doses or confirmed intolerance to medications; (b) glomerular filtration rate estimated by the CKD-EPI (Chronic Kidney Disease Epidemiology Collaboration) creatinine equation, eGFR $<90 \mathrm{ml} / \mathrm{min}$ and/or having at least microalbuminuria); and (c) age $\geq 18$ years. Exclusion criteria were pregnancy, acute myocardial infarction, unstable angina, stroke, or transitory ischemic attack within the previous 6 months; stenosis of the carotid artery $>70 \%$. All patients involved in this study were treated for hypertension for at least one year. Baseline medication was unchanged for at least 3 months before the implantation of the device.

For BAT, the Barostim neo ${ }^{\mathrm{TM}}$ (CVRx, Minneapolis, USA) was used as described previously $[21,22]$. The BAT device consists of a lead, which is sutured directly on carotis sinus, and a pulse generator implanted in an infraclavicular position by performing a minimal-invasive procedure, including intraoperative testing for optimal placement of the lead for BP response [21, 22]. The optimal response during the lead position was assumed if 30 seconds of electrical stimulation $(125 \mu \mathrm{s}, 6 \mathrm{mV}, 80 \mathrm{~Hz})$ of the carotid sinus reduces SBP by at least $10 \mathrm{~mm} \mathrm{Hg}$ and heart rate by 5 beats/min. BAT was initiated 4 weeks after the implant and the stimulation was individually increased by the adaption of programmed parameters during the monthly follow-up. Study visits were performed before the BAT implantation and 6 months after BAT activation, while BAT was ongoing in all investigated patients. Modification of antihypertensive medication by the treating physician was allowed during the observation period to adjust according to the individual office and/or BP self-measurements. All patients provided informed consent before the initiation of the protocol-mandated procedures. The study has been carried out according to the Declaration of Helsinki and was approved by the local Ethical Committee of Goettingen (19/9/11). 
The following variables were monitored during the follow-up period: systolic and diastolic office BP, number of antihypertensive medications, eGFR, proteinuria, albuminuria, aldosterone, renin as well as urinary sodium.

Retrospective analysis of patients treated in our department from 2012 to 2014 meeting inclusion criteria but refusing BAT, was performed to provide a control group. In particular, patients who had the combination of the following criteria were included: (a) meeting inclusion criteria while (b) not meeting any exclusion criteria as defined for this study and (c) patients clinical (baseline characteristics, BP data) and laboratory data (serum creatinine, proteinuria, albuminuria) were documented in a 6 months followup period.

\section{Blood Pressure Analysis}

BP measurements were obtained in a sitting position with the patient's arm supported at the level of the heart. The optimal cuff size was determined by a prior measurement of the upper arm circumference. Office BP assessments were done at the same time and by the same investigator on each occasion. The mean of the last 3 readings was used as the office cuff pressure.

It is known that for nonrandomized antihypertensive trials, reduction in ambulatory BP is smaller than the office BP drops because of either overestimation of baseline office BP and/or underestimation of final office BP [23]. To investigate changes in ambulatory $\mathrm{BP}$, ambulatory blood pressure measurement (ABPM) was performed. ABPM and heart rate monitoring was performed with a validated device (Spacelabs 992010 recorder; Spacelabs Healthcare, Nürnberg, Germany). The devices were programmed to obtain measurements every $15 \mathrm{~min}$ from 6 a.m. to 10 p.m., and every 30 min from 10 p.m. to 6 a.m. Patients were asked to continue their regular activities. Only recordings with at least $80 \%$ valid measurements were accepted.

Patients with a systolic BP (SBP) reduction of $\geq 10 \mathrm{~mm} \mathrm{Hg}$ in office-base measurements and/or $\geq 5 \mathrm{~mm} \mathrm{Hg}$ in ABPM average were subsequently defined as responders to BAT [24].

\section{Routine Analyses}

Plasma sodium, creatinine, proteinuria, and albuminuria as well as urine sodium were analyzed by standard methods. Second morning midstream urine was used. Conditions for baseline and follow-up proteinuria determination were similar (same time of the day, physical activity, diet). Urine samples were collected, centrifuged at $1,000 \mathrm{~g}$ for $10 \mathrm{~min}$ at $4{ }^{\circ} \mathrm{C}$ to remove cell debris and casts. The CKD-EPI creatinine equation, CKD-EPI cystatin $\mathrm{C}$ equation, and CKD-EPI creatinine-cystatin $\mathrm{C}$ equation were calculated by the formulas described previously [25]. Serum aldosterone and renin concentration were analyzed by commercial tests from IBL International (Hamburg, Germany) and Diasorin Deutschland GmbH (Dietzenbach, Germany) according to the protocols provided by the manufacturer. Fractioned sodium excretion was calculated by the formula (Urine sodium $\times$ plasma creatinine) / (Plasma sodium $\times$ urine creatinine). 24-hour urinary sodium excretion was estimated from a fasting morning sample using the Kawasaki-formula, which has been shown to provide a reliable estimation of 24-hour sodium excretion in patients with hypertension taking antihypertensive drugs $[26,27]$. Twenty four hour sodium excretion was additionally adjusted for the CKD-EPI cystatin C and CKD-EPI creatinine $\mathrm{C}$ equation.

\section{Statistics}

The data were evaluated using the statistical Software Statistica 10 and Microsoft Excel 2010. Baseline data were compared between BAT and the control group using either an independent samples $t$-test for means or a Chi-squared test for proportions. To analyze the potential differences between baseline and 6 -months in the investigated variables, either a paired 2 -sided $t$ test or a Wilcoxon matched pairs test was used, depending on the shape of the data. Therefore, a Shapiro-Wilk-test was used to test if data were normally distributed. To investigate the potential confounding factors, analysis of variance (ANOVA) was performed.

The Chi-squared test was used for comparing categorical variables. Data were reported as mean \pm standard deviation (SD) or as median (interquartile range (IQR)) for baseline and 6-months values as appropriated. The Pearson's correlation coefficient was used to describe the relationship between two metric variables; in some cases, extreme values were excluded. The threshold for statistical significance was chosen to be $\mathrm{p}<0.05$.

\section{Results}

\section{Patients}

Twenty-three CKD patients with therapy-resistant hypertension were analyzed. Baseline data are shown in table 1 . This cohort included patients with chronic renal failure stage $\geq 3$ or higher $(n=15)$ including one patient with ESRD stage 5D and one renal transplant recipient stage 4T. Six patients had a history of renal denervation, which was performed at least 9 months prior implantation of BAT. Two-factorial ANOVA revealed that prior renal denervation was not a confounding factor for the change of office SBP ( $p=0.76)$, change of albuminuria $(p=0.92)$, and change of proteinuria $(p=0.60)$. Women had a significant lower CKD stage $(\mathrm{p}<0.01)$, but a bias of this variable on BAT effects (reduction of proteinuria $\mathrm{p}=$ 0.71 ; reduction of ambulatory $\mathrm{SBP} p=0.72$ ) could be ruled out. Except the distribution of gender, which did not affect the changes of the investigated variables proteinuria $(\mathrm{p}=0.82)$, albuminuria $(\mathrm{p}=0.26)$, eGFR $(\mathrm{p}=$ $0.17)$, and mean arterial BP $(\mathrm{p}=0.11)$, patients' demographic and clinical characteristics did not differ between the BAT and control group (table 1).

\section{Blood Pressure and Antihypertensive Treatment}

Table 2 shows office blood pressure, ABPM data, and antihypertensive treatment at baseline and after 6 months. Patients were hypertensive with a mean office blood pressure of $161 \pm 31.9 \mathrm{~mm} \mathrm{Hg}$ over $87.4 \pm 15.2 \mathrm{~mm} \mathrm{Hg}$ and a mean ABPM pressure of $142.3 \pm 16.4 \mathrm{~mm}$ Hg over $79.6 \pm$ $11.7 \mathrm{~mm} \mathrm{Hg}$ diastolic, despite a mean number of 6.6 prescribed antihypertensive drugs. 
Table 1. Patients' characteristics at baseline

\begin{tabular}{|c|c|c|c|}
\hline $\mathrm{n}$ & $\operatorname{BAT}(\mathrm{n}=23)$ & Control $(\mathrm{n}=21)$ & $\mathrm{p}$ \\
\hline \multicolumn{4}{|l|}{ Gender } \\
\hline Male & $11(48)$ & $18(86)$ & 0.02 \\
\hline Female & $12(52)$ & $3(14)$ & \\
\hline Age, years & $60.9 \pm 9.8$ & $60.4 \pm 10.9$ & 0.88 \\
\hline $\mathrm{BMI}, \mathrm{kg} / \mathrm{m}^{2}$ & $32.8 \pm 6.1$ & n.a. & \\
\hline Prior renal denervation & $6(26)$ & $4(19)$ & 0.58 \\
\hline Number of antihypertensives & $6.6 \pm 1.6$ & $5.8 \pm 1.3$ & 0.07 \\
\hline $\mathrm{eGFR}, \mathrm{ml} / \mathrm{min}$ & $63.6 \pm 27.8$ & $62.8 \pm 25.0$ & 0.17 \\
\hline Proteinuria, mg/g creatinine & $283.9(83.5-555.1)$ & $134.4(73.7-187.7)$ & 0.82 \\
\hline Albuminuria, mg/g creatinine & $47.7(16.9-261.6)$ & $16.9(9.5-49.6)$ & 0.26 \\
\hline Mean BP, mm Hg & $116.9 \pm 20.9$ & $112.8 \pm 12.0$ & 0.11 \\
\hline \multicolumn{4}{|l|}{ Type of nephropathy (abs. (\%)) } \\
\hline Hypertensive nephropathy & $15(65)$ & $12(57)$ & 0.58 \\
\hline Diabetic/hypertensive nephropathy & $6(26)$ & $8(38)$ & 0.60 \\
\hline IgA-Nephritis & $2(9)$ & $1(5)$ & 0.61 \\
\hline Renal transplantation & $1(4)$ & $0(0)$ & 0.33 \\
\hline CKD-stage (CKD-EPI equation) & & & 0.58 \\
\hline I & $2(9)$ & $4(19)$ & \\
\hline II & $6(26)$ & $6(29)$ & \\
\hline III & $9(39)$ & $9(43)$ & \\
\hline IV & $5(21)$ & $2(10)$ & \\
\hline VD & $1(4)$ & $0(0)$ & \\
\hline \multicolumn{4}{|l|}{ Relevant concomitant diseases } \\
\hline Congestive heart failure & $2(9)$ & $0(0)$ & 0.17 \\
\hline Coronary heart disease & $7(30)$ & $7(33)$ & 0.84 \\
\hline Diabetes mellitus & $6(26)$ & $8(38)$ & 0.39 \\
\hline Hyperlipoproteinemia & $18(78)$ & $12(57)$ & 0.13 \\
\hline History of smoking & $17(74)$ & $12(57)$ & 0.24 \\
\hline
\end{tabular}

Values are mean \pm SD or n (\%). n.a. = Not applicable; $C K D=$ chronic kidney disease; CKD-stage IVT = recipients of renal transplant in CKD stage IV; CKD-stage VD = patients with CKD-stage 5 on hemodialysis; CKD$\mathrm{EPI}=$ chronic kidney disease epidemiology collaboration; BMI = body mass index.

After 6 months of BAT, the office systolic and diastolic BP decreased significantly $(\mathrm{p}<0.01)$. The mean decrease of systolic ABPM was $-5.7 \pm 15.4 \mathrm{~mm} \mathrm{Hg}$ ( $\mathrm{p}=$ 0.08 ). Regarding the mean change and SD in systolic ABPM observed in this study, power analysis revealed a sample size of 53 patients with a power of $80 \%$ and $\alpha=$ 0.05 to detect a statistically significant difference between baseline and month 6 . The mean number of prescribed antihypertensive drugs decreased to $6.1 \pm 1.7(\mathrm{p}=0.02)$. The number and/or the dose of antihypertensive drugs could be reduced in 16 of 23 patients (70\%). According to published recommendations, 4 (17\%) patients were classified as nonresponders to BAT [24]. There was no significant change in office mean $B P(112.8 \pm 12.0$ vs. $111.5 \pm$ $12.3 \mathrm{~mm} \mathrm{Hg} ; \mathrm{p}=0.66)$ or in the number of prescribed antihypertensives $(5.8 \pm 1.3$ vs. $5.9 \pm 1.4 ; \mathrm{p}=0.19)$ in control patients throughout 6 months.

\section{Proteinuria}

Results on proteinuria are shown in table 3 and figure 1. At baseline, micro-/macroalbuminuria was present in $15 / 23(65 \%)$ of the patients. Proteinuria was decreased after 6 months of BAT by a median $-29.2 \%(-67.6 \pm$ $42.1 \%)(\mathrm{p}=0.01)$ and albuminuria by a median $-19.0 \%$ $(-60.9 \pm 5.1 \%)(\mathrm{p}=0.01)$, while these parameters remained unchanged in controls (proteinuria $(134.4 \mathrm{mg} / \mathrm{g}$ creatinine (73.7-187.7) vs. $112.8 \mathrm{mg} / \mathrm{g}$ creatinine (60.3$250.0) ; \mathrm{p}=0.55)$, albuminuria $16.9 \mathrm{mg} / \mathrm{g}$ creatinine (9.5$49.6)$ vs. $17.9 \mathrm{mg} / \mathrm{g}$ creatinine $(9.3-74.8) ; \mathrm{p}=0.59)$. The class of micro-/macroalbuminuria also significantly improved after 6 months of BAT ( $\mathrm{p}=0.047$ ) (fig. 1). Additionally, we correlated the decrease of SBP with the percentage decrease of proteinuria and albuminuria and observed a significant positive correlation between the decrease in SBP and albuminuria $(\mathrm{r}=0.452 ; \mathrm{p}=0.045)$. 
Table 2. Office blood pressure, ABPM and antihypertensive drugs

\begin{tabular}{|c|c|c|c|c|c|c|}
\hline \multicolumn{7}{|l|}{ Office BP } \\
\hline Systolic, mm Hg & $161.0 \pm 31.9$ & $144.0 \pm 32.3$ & $<0.01$ & $155.3 \pm 19.1$ & $153.6 \pm 17.4$ & 0.70 \\
\hline Diastolic, mm Hg & $87.4 \pm 15.2$ & $77.7 \pm 17.1$ & $<0.01$ & $84.4 \pm 12.0$ & $83.4 \pm 13.0$ & 0.70 \\
\hline \multicolumn{7}{|l|}{$\mathrm{ABPM}^{*}, \mathrm{n}=22$} \\
\hline Systolic, mm Hg & $142.3 \pm 16.4$ & $136.0 \pm 23.7$ & 0.08 & n.a. & n.a. & \\
\hline Diastolic, mm Hg & $79.6 \pm 11.7$ & $74.8 \pm 16.4$ & 0.09 & n.a. & n.a. & \\
\hline Mean, $\mathrm{mm} \mathrm{Hg}$ & $102.6 \pm 12.3$ & $97.2 \pm 18.6$ & 0.08 & n.a. & n.a. & \\
\hline Maximum, mm $\mathrm{Hg}$ & $179.1 \pm 20.7$ & $179.2 \pm 33.3$ & 0.98 & n.a. & n.a. & \\
\hline Pulse pressure, $\mathrm{mm} \mathrm{Hg}$ & $59.9 \pm 18.6$ & $58.5 \pm 18.8$ & 0.30 & n.a. & n.a. & \\
\hline ACE-inhibitor & $10(44)$ & $10(44)$ & & $10(48)$ & $10(48)$ & \\
\hline AT1-blocker & $13(57)$ & $13(57)$ & & $13(62)$ & $13(62)$ & \\
\hline Aldosterone receptor antagonist & $4(17)$ & $3(13)$ & & $6(26)$ & $6(26)$ & \\
\hline Renin-inhibitor & $7(30)$ & $6(26)$ & & $3(14)$ & $3(14)$ & \\
\hline Beta-blocker & $18(78)$ & $17(74)$ & & $16(76)$ & $16(76)$ & \\
\hline Calcium-channel blockers & $17(74)$ & $17(74)$ & & $17(81)$ & $17(81)$ & \\
\hline Loop diuretics & $13(57)$ & $14(61)$ & & $11(52)$ & $13(62)$ & \\
\hline Thiazide & $20(87)$ & $18(78)$ & & $13(62)$ & $13(62)$ & \\
\hline Alpha-1 receptor blocker & $19(83)$ & $14(61)$ & & $14(67)$ & $14(67)$ & \\
\hline Alpha-2-adrenergic agonist & $20(87)$ & $16(70)$ & & $16(76)$ & $16(76)$ & \\
\hline $\begin{array}{l}\text { Antihypertensive withdrawal } \\
\text { and/or dose reduction }\end{array}$ & & $16 / 23(70)$ & & & $0 / 21(0)$ & \\
\hline
\end{tabular}

Values are mean $\pm \mathrm{SD}$ or $\mathrm{n}(\%) .{ }^{*} \mathrm{n}=22$ for $24 \mathrm{~h}$ ambulatory blood pressure measurement $(\mathrm{ABPM})$ data. $\mathrm{BP}=\mathrm{Blood}$ pressure.

Changes of ambulatory SBP as well as the change of proteinuria showed a negative correlation with baseline proteinuria by $\mathrm{r}=-0.398(\mathrm{p}=0.08)$ and $\mathrm{r}=-0.6998(\mathrm{p}<0.01)$, respectively (correlations are shown in online suppl. fig. 1; for all online suppl. material, see www.karger.com/ doi/10.1159/000368723).

\section{Excretory Renal Function}

Serum creatinine $(p=0.66)$, eGFR-MDRD $(p=0.82)$, and CKD-EPI creatinine equation $(\mathrm{p}=0.98)$ did not differ in the follow-up compared to baseline. After 6 months of BAT, the mean change in cystatin C and CKD-EPI creatinine cystatin $C$ equation were $-0.14 \pm 0.40(p=0.10)$, $+3.3 \pm 9.3(\mathrm{p}=0.11)$, respectively, whereas CKD-EPI cystatin $\mathrm{C}$ equation significantly increased $(+6.7 \pm 12.7 ; \mathrm{p}=$ $0.02)$. Data are summarized in table 3 . In controls, serum creatinine $(1.35 \pm 0.51 \mathrm{mg} / \mathrm{dl}$ vs. $1.55 \pm 0.75 \mathrm{mg} / \mathrm{dl} ; \mathrm{p}=$
$0.04)$ and eGFR $(62.8 \pm 25.0 \mathrm{ml} / \mathrm{min}$ vs. $54.5 \pm 23.4 \mathrm{ml} /$ min; $\mathrm{p}<0.01$ ) were significantly impaired 6-months after the first consultation.

\section{Renin-Aldosterone Axis and Sodium Excretion}

$\operatorname{Renin}(\mathrm{p}=0.32)$, aldosterone ( $\mathrm{p}=0.90)$, and the aldosterone-/renin-quotient $(\mathrm{p}=0.39)$ remained unchanged after 6 months of BAT treatment. Though the prescription rate of diuretics did not change after 6 months of BAT, fractioned sodium excretion and 24-hour sodium excretion calculated by the Kawasaki formula tended to increase without a statistically significant change. Twenty four hour sodium excretion adjusted to CKD creatinine equation as well to CKD cystatin Cequation showed a trend to increase from $2.13(1.32-3.97)$ to $2.68(1.44-4.54) \mathrm{mmol} / \mathrm{day} / \mathrm{ml} / \mathrm{min}(\mathrm{p}=$ $0.10)$ and from $2.66 \pm 1.65$ to $3.00 \pm 2.71 \mathrm{mmol} / \mathrm{day} / \mathrm{ml} / \mathrm{min}$ $(\mathrm{p}=0.39)$, respectively. Data are summarized in table 3 . 
Table 3. Functional renal parameters at baseline and after 6 months of BAT

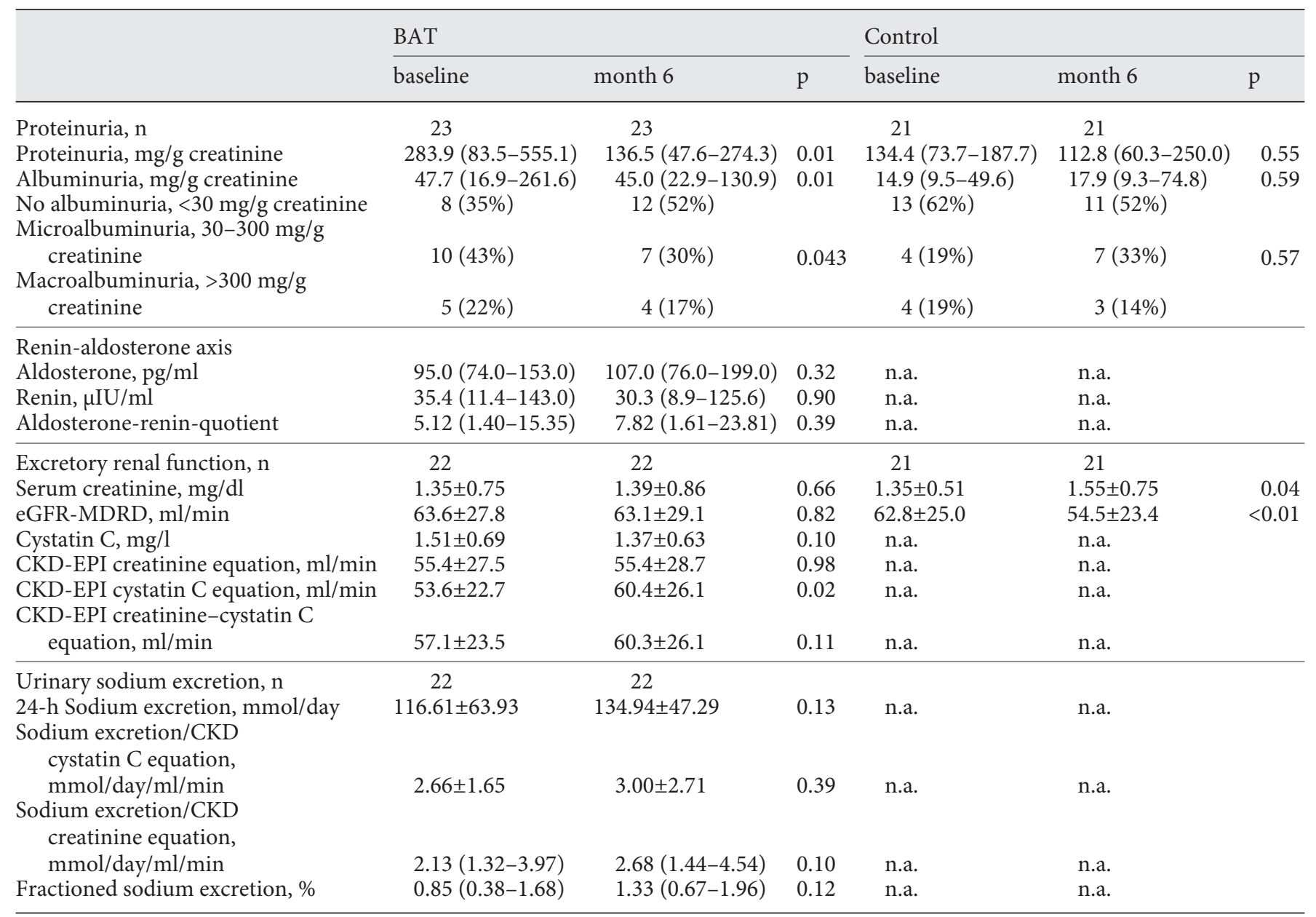

Values described by absolute and percentage proportions, mean \pm SD or median (IQR). CKD-EPI = Chronic kidney disease epidemiology collaboration; GFR = glomerular filtration rate; serum creatinine in $\mathrm{mg} / \mathrm{dl}$ to $\mathrm{mol} / \mathrm{l}, \times 88.4$.

Impact of Baseline CKD Stage on BAT Effects

ANOVA analysis for CKD stage I-V revealed no effect on the change of SBP reduction $(p=0.28)$, whereas the percentage reduction of proteinuria is affected by the CKD stage I to IV $(\mathrm{p}=0.02)$ (stage VD was excluded from analysis). Proteinuria only decreased in CKD stages III and IV $(-42.5 \pm 44.2 \%)(\mathrm{p}<0.01)$ (fig. 1). Therefore, the percentage proteinuria decrease correlated with baseline CKD-EPI cystatin $\mathrm{C}$ equation with $\mathrm{r}=0.454(\mathrm{p}=0.03)$.

\section{Discussion}

This is the first prospective study on BAT for the treatment of resistant hypertension in CKD patients. Our study has three major findings:
1. BAT significantly lowers office BP in therapeuticresistant hypertensive patients with CKD. 2. BAT reduces proteinuria/albuminuria BP-dependent and independently in patients with CKD. 3. The anticipated decrease in renal excretory function did not occur after 6 months of BAT.

Treatment of resistant hypertension in CKD is difficult. Nearly $40 \%$ of patients with CKD have an uncontrolled BP (in patients with macroalbuminuria up to $80 \%$ ) [28] and almost the same proportion presents difficulties in the optimization of BP, needing 4 or more antihypertensive drugs in everyday conditions [29].

Actually, the amount of proteinuria $[30,31]$ and its reduction by treatment are predictive of renal outcome [31]. A therapeutic reduction of proteinuria by 20 to $50 \%$ or more than $50 \%$ after half a year reduces the risk 


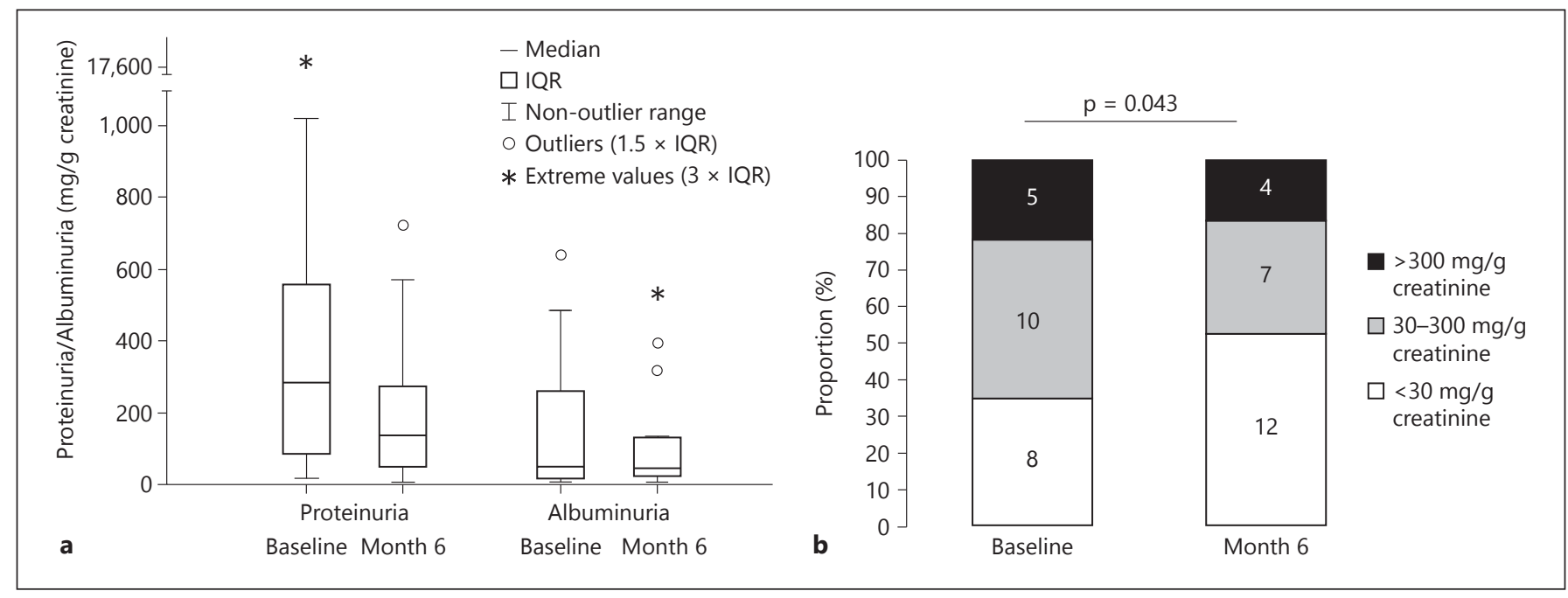

Fig. 1. Baroreflex activation therapy (BAT) significantly reduces proteinuria and albuminuria. a proteinuria baseline: $283.9 \mathrm{mg} / \mathrm{g}$ creatinine (83.5-555.1) month 6: $136.5 \mathrm{mg} / \mathrm{g}$ creatinine (47.6274.3); albuminuria baseline: $47.7 \mathrm{mg} / \mathrm{g}$ creatinine (16.9-261.6) month 6: $45.0 \mathrm{mg} / \mathrm{g}$ creatinine (22.9-130.9) (both p < 0.05). b BAT influences albuminuria - distribution of albuminuria degree at baseline and at months 6 after starting BAT in patients with resistant hypertension and chronic kidney disease (CKD), $\mathrm{n}=23$. c Changes of proteinuria depends on CKD stage $-\Delta$ Proteinuria (\%) in patients with CKD stage I and II $(69.0 \pm 43.0 \%)(n=8)$ compared to patients with CKD III and IV $(-44.5 \pm 44.2 \%)(\mathrm{n}=14)$, $\mathrm{p}<0.01$.

of ESRD by nearly 50 or $75 \%$, respectively [31]. Patients with therapeutic-resistant hypertension and CKD are considered high-risk patients for ESRD and cardiovascular events, but the treatment is challenging as many drugs as well as some interventional procedures (e.g., renal denervation) are contraindicated in this patient population. Our study shows, that BAT in this patient population is not only safe, but has the potential to decrease BP as well as proteinuria in this high-risk patient population. Hence, our study has immediate clinical consequences given the rising numbers of this patient population. We found a significant median reduction of proteinuria by $29.2 \%$, which in subgroup analyses showed to be confined to patients with CKD stage III and IV. Potential antiproteinuric mechanisms might have been based on the improvement of renal hemody-

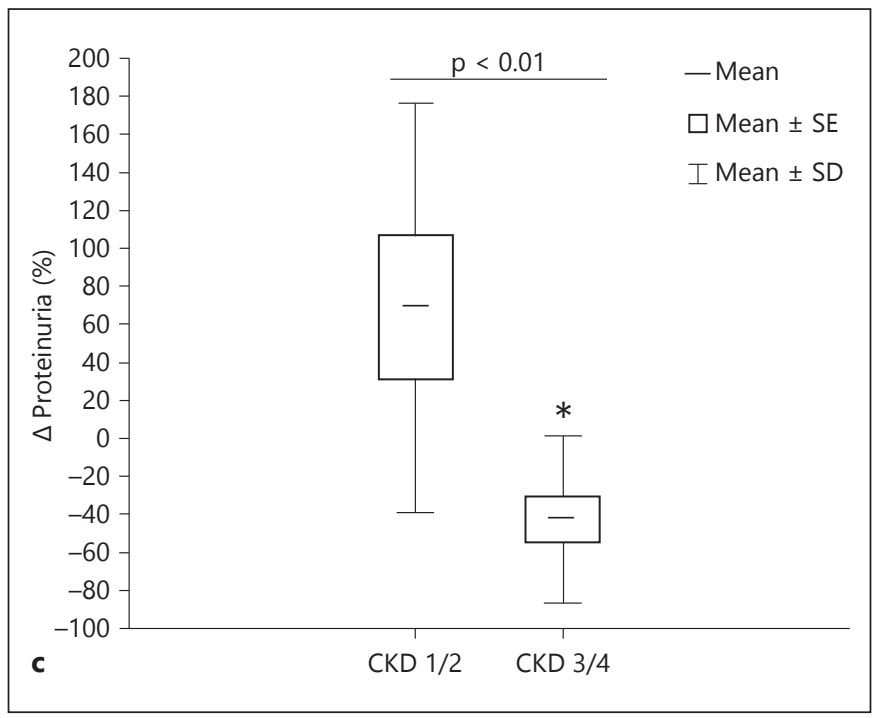

namic and non-hemodynamic effects such as local RAAS activation and inhibition of sympathetic activity within the kidney $[13,32]$. Obviously, SBP and albuminuria response in antihypertensive trials does not always run in parallel $[33,34]$. Though cardiovascular risk is strongly correlated to BP, there is also a clear dependence on the achieved albuminuria regardless of the level of SBP. With regard to renal function, the residual level of albuminuria in patients who had reached SBP target was strongly associated with the risk of ESRD [35]. Thus, it is of importance to improve cardiovascular outcome and preserve renal function to perform a dual approach of lowering both BP and albuminuria [33]. The study does not exclude the well-established correlation between $\mathrm{BP}$ and proteinuria reduction, but suggests that BAT might additionally contribute to cardiovascu- 
lar risk reduction by improving proteinuria also BP-independently. Elevated sympathetic nervous activity is suggested to constitute an important mechanism contributing to the onset and maintenance of renal injury. Therefore, inhibition of the sympathetic nervous system might aid in the prevention and treatment of renal injury, CKD, and ESRD [36].

In fact, sympathetic overdrive shows an inverse relationship with GFR [37]. Of note, in our study there is a significant correlation between baseline proteinuria and ambulatory SBP reduction as well as a pronounced antiproteinuric effect in higher CKD stages. On the basis of the AASK trial [31] an annual GFR decrease of $2.95 \mathrm{ml} /$ min and a $1.1 \%$ rate of ESRD could be anticipated in our cohort. This was corroborated by data achieved in controls refusing BAT. Depending on the applied GFR estimation formula, the excretory renal function remained at least unchanged in our cohort with a non-significant decrease of $0.5 \mathrm{ml} / \mathrm{min}$ in eGFR (MDRD) formula, while other equations showed a trend toward improvement up to a maximal, significant increase of $6.8 \mathrm{ml} / \mathrm{min}$ in all patients using the CKD-EPI cystatin C equation. Notably, cystatin C-based CKD equations have been shown to have a greater accuracy and precision [25]. This is in contrast to extended data in the Rheos pivotal trial, which showed an eGFR decrease of $5 \mathrm{ml} / \mathrm{min}$ after 6 and of 11 $\mathrm{ml} / \mathrm{min}$ after 12 months. Interestingly, eGFR-reduction was restricted to patients with a baseline eGFR $>60 \mathrm{ml} /$ $\min [15]$.

Therapeutic strategies for patients with arterial hypertension and CKD are mainly based on interventions in the RAAS-system as well as in volume homeostasis. There are no prospective studies or evidence-based guidelines to date on how to optimize antihypertensive regimen in CKD patients with uncontrolled BP even under a treatment with 6 to 7 antihypertensive drugs as in our cohort.

Our study has some potential limitations. It is a single center, nonrandomized trial and the sample size is small, which is the consequence of the current availability of the method as well as ethical reasons to withhold an efficacious therapy from high-risk patients with resistant hypertension. As shown for several interventional hypertension trials including the recent Symplicity-3 trial, the use of sham group is critical in defining real outcomes [38]. Though being aware of the potential confounding factors of an absent randomized control group, the present pilot trial was not designed to be an interventional study, which can be performed only with a great afford in a multicenter design. As a reasonable compromise to investigate Hawthorne effect by treating patients in a center for hypertension as well as regression to the mean on the investigated parameters, $21 \mathrm{pa}-$ tients meeting the inclusion criteria but refusing BAT served as a control group. Because of the relative small number of patients, minor differences between the treatment group and the control group might not have reached statistical significance. Though renoprotective effects are ascribed to most antihypertensive medications, the withdrawal might also have influenced functional renal data. For analysis of the eGFR decline, the duration of the observation period is relatively short and a longer follow-up is foreseen. However, this study was performed in a difficult-to-treat class of patients with severe hypertension were antihypertensives therapy can impact renal function in a negative way. Since sympathetic overactivity contributes to increased CV risk and progression of renal disease, via BP-dependent as well as $\mathrm{BP}$-independent mechanisms, our data provide evidence that BAT might protect individuals with CKD and resistant hypertension, which are supposed to have increased levels of sympathetic nerve activity. In conclusion, BAT might represent in future, in addition to its use in resistant hypertension, an adequate therapy for CKD patients. The present study shows, that BAT reduces proteinuria and albuminuria and leads to a stabilization of CKD progression, indicating that BAT might be a potential factor to decelerate the progress of renal failure. The cohort in our study does not allow the analysis of clinical outcome. Precise evaluation of potential nephroprotective effects of BAT in patients with resistant hypertension and CKD will also need randomized controlled trials using sham procedures to respect the double blind design.

\section{Acknowledgment}

The authors thank Mrs. C. Biegler for assistance, Dr. D. Zenker, Dept. of thoracic-cardiac-vascular surgery, for BAT implantation, Mr. H.-J. Helms for statistical review and the employees of CVRx for technical support. Research program, Faculty of Medicine, Georg-August-University Goettingen, to MW and a research grant from CVRx to MK and MW.

\section{Disclosure Statement}

MW and MK declare lecture fees and/or funding of CVRx. RW declares having received lecture fees and enumeration for including subjects into clinical trials from CVRx. LL, CS, and GH have nothing to declare. 


\section{References}

1 Bisognano JD, Bakris G, Nadim MK, Sanchez L, Kroon AA, Schafer J, de Leeuw PW, Sica DA: Baroreflex activation therapy lowers blood pressure in patients with resistant hypertension: results from the double-blind, randomized, placebo-controlled rheos pivotal trial. J Am Coll Cardiol 2011;58:765-773.

$\checkmark 2$ Kidney Disease: Improving Global Outcomes (KDIGO) Blood Pressure Work Group: KDIGO clinical practice guideline for the management of blood pressure in chronic kidney disease. Kidney Int Suppl 2012;2:337-414.

- 3 Calhoun DA, Jones D, Textor S, Goff DC, Murphy TP, Toto RD, White A, Cushman WC, White W, Sica D, Ferdinand K, Giles TD, Falkner B, Carey RM: Resistant hypertension: Diagnosis, evaluation, and treatment: a scientific statement from the American Heart Association Professional Education Committee of the Council for High Blood Pressure Research. Circulation 2008;117:e510-e526.

4 Sarafidis PA, Bakris GL: Resistant hypertension: an overview of evaluation and treatment. J Am Coll Cardiol 2008;52:1749-1757.

$\checkmark 5$ Sim JJ, Bhandari SK, Shi J, Liu IL, Calhoun DA, McGlynn EA, Kalantar-Zadeh K, Jacobsen SJ: Characteristics of resistant hypertension in a large, ethnically diverse hypertension population of an integrated health system. Mayo Clin Proc 2013;88:1099-1107.

6 Sarafidis PA, Ruilope LM: Aggressive blood pressure reduction and renin-angiotensin system blockade in chronic kidney disease: time for re-evaluation? Kidney Int 2014;85:536546.

7 Grassi G, Seravalle G, Brambilla G, Cesana F, Giannattasio C, Mancia G: Similarities and differences between renal sympathetic denervation and carotid baroreceptor stimulation. Curr Vasc Pharmacol 2014;12:63-68.

8 Ruilope LM, Bakris GL: Renal function and target organ damage in hypertension. Eur Heart J 2011;32:1599-1604.

-9 Grassi G, Seravalle G, Dell'Oro R, Mancia G: Sympathetic mechanisms, organ damage, and antihypertensive treatment. Curr Hypertens Rep 2011;13:303-308.

10 Lohmeier TE, Iliescu R, Liu B, Henegar JR, Maric-Bilkan C, Irwin ED: Systemic and renal-specific sympathoinhibition in obesity hypertension. Hypertension 2012;59: 331-338.

11 Grassi G, Seravalle G, Ghiadoni L, Tripepi G, Bruno RM, Mancia G, Zoccali C: Sympathetic nerve traffic and asymmetric dimethylarginine in chronic kidney disease. Clin J Am Soc Nephrol 2011;6:2620-2627.

12 Kiuchi MG, Maia GL, de Queiroz Carreira MA, Kiuchi T, Chen S, Andrea BR, Graciano ML, Lugon JR: Effects of renal denervation with a standard irrigated cardiac ablation catheter on blood pressure and renal function in patients with chronic kidney disease and resistant hypertension. Eur Heart J 2013;34: 2114-2121.
13 Mahfoud F, Cremers B, Janker J, Link B, Vonend O, Ukena C, Linz D, Schmieder R, Rump LC, Kindermann I, Sobotka PA, Krum H, Scheller B, Schlaich M, Laufs U, Böhm M: Renal hemodynamics and renal function after catheter-based renal sympathetic denervation in patients with resistant hypertension. Hypertension 2012;60:419-424.

14 Scheffers IJ, Kroon AA, Schmidli J, Jordan J, Tordoir JJ, Mohaupt MG, Luft FC, Haller H, Menne J, Engeli S, Ceral J, Eckert S, Erglis A, Narkiewicz K, Philipp T, de Leeuw PW: Novel baroreflex activation therapy in resistant hypertension: results of a European multicenter feasibility study. J Am Coll Cardiol 2010;56:1254-1258.

15 Alnima T, de Leeuw PW, Tan FE, Kroon AA; Rheos Pivotal Trial Investigators: Renal responses to long-term carotid baroreflex activation therapy in patients with drug-resistant hypertension. Hypertension 2013;61:1334-1339.

16 Doumas M, Faselis C, Tsioufis C, Papademetriou V: Carotid baroreceptor activation for the treatment of resistant hypertension and heart failure. Curr Hypertens Rep 2012;14: 238-246.

17 Chobanian AV, Bakris GL, Black HR, Cushman WC, Green LA, Izzo JL Jr, Jones DW, Materson BJ, Oparil S, Wright JT Jr, Roccella EJ; Joint National Committee on Prevention, Detection, Evaluation, and Treatment of High Blood Pressure; National heart, lung, and blood institute; national high blood pressure education program coordinating committee: Seventh report of the Joint National Committee on Prevention, Detection, Evaluation, and Treatment of High Blood Pressure. Hypertension 2003;42:1206-1252.

18 Mancia G, Fagard R, Narkiewicz K, Redon J, Zanchetti A, Bohm M, Christiaens T, Cifkova R, De Backer G, Dominiczak A, Galderisi M, Grobbee DE, Jaarsma T, Kirchhof P, Kjeldsen SE, Laurent S, Manolis AJ, Nilsson PM, Ruilope LM, Schmieder RE, Sirnes PA, Sleight P, Viigimaa M, Waeber B, Zannad F: 2013 ESH/ESC Guidelines for the management of arterial hypertension: the Task Force for the management of arterial hypertension of the European Society of Hypertension (ESH) and of the European Society of Cardiology (ESC). J Hypertens 2013;31:1281-1357.

19 Radhakrishnan J, Cattran DC: The KDIGO practice guideline on glomerulonephritis: reading between the (guide)lines - application to the individual patient. Kidney Int 2012;82:840-856.

20 Kidney Disease Outcomes Quality Initiative (K/DOQI): K/DOQI clinical practice guidelines on hypertension and antihypertensive agents in chronic kidney disease. Am J Kidney Dis 2004;43(5 suppl 1):S1-S290.

21 Hoppe UC, Brandt MC, Wachter R, Beige J, Rump LC, Kroon AA, Cates AW, Lovett EG, Haller H: Minimally invasive system for baroreflex activation therapy chronically lowers blood pressure with pacemaker-like safety profile: results from the Barostim neo trial. J Am Soc Hypertens 2012;6:270-276.

22 Tordoir JH, Scheffers I, Schmidli J, Savolainen H, Liebeskind U, Hansky B, Herold U, Irwin E, Kroon AA, de Leeuw P, Peters TK, Kieval R, Cody R: An implantable carotid sinus baroreflex activating system: surgical technique and short-term outcome from a multicenter feasibility trial for the treatment of resistant hypertension. Eur J Vasc Endovasc Surg 2007;33:414-421.

23 Howard JP, Nowbar AN, Francis DP: Size of blood pressure reduction from renal denervation: insights from meta-analysis of antihypertensive drug trials of 4,121 patients with focus on trial design: the CONVERGE report. Heart 2013;99:1579-1587.

24 Mahfoud F, Ukena C, Schmieder RE, Cremers B, Rump LC, Vonend O, Weil J, Schmidt M, Hoppe UC, Zeller T, Bauer A, Ott C, Blessing E, Sobotka PA, Krum H, Schlaich M, Esler M, Böhm M: Ambulatory blood pressure changes after renal sympathetic denervation in patients with resistant hypertension. Circulation 2013;128:132-140.

25 Inker LA, Schmid CH, Tighiouart H, Eckfeldt JH, Feldman HI, Greene T, Kusek JW, Manzi J, Van Lente F, Zhang YL, Coresh J, Levey AS; CKD-EPI Investigators: Estimating glomerular filtration rate from serum creatinine and cystatin C. N Engl J Med 2012;367:20-29.

26 Kawasaki T, Itoh K, Uezono K, Sasaki H: A simple method for estimating $24 \mathrm{~h}$ urinary sodium and potassium excretion from second morning voiding urine specimen in adults. Clin Exp Pharmacol Physiol 1993;20:7-14.

27 Kawamura M, Kusano Y, Takahashi T, Owada $\mathrm{M}$, Sugawara T: Effectiveness of a spot urine method in evaluating daily salt intake in hypertensive patients taking oral antihypertensive drugs. Hypertens Res 2006;29:397-402.

28 Fraser SD, Roderick PJ, McIntyre NJ, Harris S, McIntyre CW, Fluck RJ, Taal MW: Suboptimal blood pressure control in chronic kidney disease stage 3: baseline data from a cohort study in primary care. BMC Fam Pract 2013;14:88

29 Egan BM, Zhao Y, Li J, Brzezinski WA, Todoran TM, Brook RD, Calhoun DA: Prevalence of optimal treatment regimens in patients with apparent treatment-resistant hypertension based on office blood pressure in a community-based practice network. Hypertension 2013;62:691-697.

30 Cravedi P, Ruggenenti P, Remuzzi G: Proteinuria should be used as a surrogate in CKD. Nat Rev Nephrol 2012;8:301-306.

-31 Lea J, Greene T, Hebert L, Lipkowitz M, Massry S, Middleton J, Rostand SG, Miller E, Smith W, Bakris GL: The relationship between magnitude of proteinuria reduction and risk of end-stage renal disease: results of the African American study of kidney disease and hypertension. Arch Intern Med 2005;165:947-953. 
32 Sobotka PA, Mahfoud F, Schlaich MP, Hoppe UC, Bohm M, Krum H: Sympatho-renal axis in chronic disease. Clin Res Cardiol 2011;100: 1049-1057.

33 Holtkamp FA, de Zeeuw D, de Graeff PA, Laverman GD, Berl T, Remuzzi G, Packham D, Lewis JB, Parving HH, Lambers Heerspink HJ: Albuminuria and blood pressure, independent targets for cardioprotective therapy in patients with diabetes and nephropathy: a post hoc analysis of the combined RENAAL and IDNT trials. Eur Heart J 2011;32:14931499.
34 Laverman GD, Andersen S, Rossing P, Navis G, de Zeeuw D, Parving HH: Renoprotection with and without blood pressure reduction. Kidney Int Suppl 2005:S54-S59.

35 Eijkelkamp WB, Zhang Z, Remuzzi G, Parving HH, Cooper ME, Keane WF, Shahinfar S, Gleim GW, Weir MR, Brenner BM, de Zeeuw $\mathrm{D}$ : Albuminuria is a target for renoprotective therapy independent from blood pressure in patients with type 2 diabetic nephropathy: post hoc analysis from the Reduction of Endpoints in NIDDM with the Angiotensin II Antagonist Losartan (RENAAL) trial. J Am Soc Nephrol 2007;18:1540-1546.

-36 Masuo K, Lambert GW, Esler MD, Rakugi H, Ogihara T, Schlaich MP: The role of sympathetic nervous activity in renal injury and end-stage renal disease. Hypertens Res 2010; 33:521-528.
37 Zoccali C, Mallamaci F, Parlongo S, Cutrupi S, Benedetto FA, Tripepi G, Bonanno G, Rapisarda F, Fatuzzo P, Seminara G, Cataliotti A, Stancanelli B, Malatino LS: Plasma norepinephrine predicts survival and incident cardiovascular events in patients with end-stage renal disease. Circulation 2002;105:1354-1359.

38 Bhatt DL, Kandzari DE, O’Neill WW, D'Agostino R, Flack JM, Katzen BT, Leon MB, Liu M, Mauri L, Negoita M, Cohen SA, Oparil S, Rocha-Singh K, Townsend RR, Bakris GL: A controlled trial of renal denervation for resistant hypertension. N Engl J Med 2014;370: 1393-1401. 